\title{
Antithrombin Activity Actual to Control Ratio Measurement
}

National Cancer Institute

\section{Source}

National Cancer Institute. Antithrombin Activity Actual to Control Ratio Measurement. NCI Thesaurus. Code C147306.

The determination of the ratio of the biological activity of antithrombin in a subject's specimen when compared to the same activity in a control specimen. The measurement may be expressed as a ratio or percentage. 